\title{
Meetings or Power Weeks? Boundary Work in a Transnational Police Project
}

\author{
Malin Åkerström \\ Lund University, Sweden \\ David Wästerfors \\ Lund University, Sweden \\ Sophia Yakhlef \\ Lund University, Sweden
}

DOI: http://dx.doi.org/10.18778/1733-8077.16.3.05

Keywords:

Occupational Culture;

Identity; Meetings;

Border Police; Project;

Bureaucracy

\begin{abstract}
Meetings are common in contemporary working life, but they are often overlooked in academic studies and sometimes defined as empty or boring by employees. Yet, the meeting society is being reproduced again and again. There seem to be hidden ways to incorporate meetings into today's working life without arousing critique about pointless activities and deviations from what should really be done. One strategy was illustrated in a study of a transnational police project. Police culture celebrates visible crime fighting, which is associated with action, physical toughness, and capturing criminals. The police officers involved in the project emphasized the need to avoid "a lot of meetings," but de facto constructed their project as meetings. Nonetheless, the project was declared a success. We analyze this paradox in terms of boundary work concerning meetings; the police officers turned some meetings into "real police work" by discursively and practically removing them from the category of bureaucracy and its associations with formalities, rigidity, and documentation. The most important example is how an "operational action group meeting" was renamed "power weeks," eradicating the very word "meeting" from the term. This was closely associated with increased informality and multi-tasking during these gatherings.
\end{abstract}

Malin Åkerström is a Professor in Sociology at the Department of Sociology, Lund University, Sweden. Her research work focuses on ethnographic studies of social control and deviance. Her most recent book is Suspicious Gifts-Bribery, Morality, and Professional Ethics, and she has also pub- lished Betrayal and Betrayers-The Sociology of Treachery and Crooks and Squares-Lifestyles of Thieves and Addicts. She has also been published in The Sociological Review, Symbolic Interaction, and Sociological Perspective.

email address: malin.akerstrom@soc.lu.se 
David Wästerfors is a Professor in Sociology at the Department of Sociology, Lund University, Sweden, and teaches in sociology and criminology. His research is often focused on interactions, institutions, emotions, and social control. He has completed three research projects with ethnographic data from Swedish detention homes (on conflicts, schooling, and violence). A related interest is qualitative methodology, shown in the book Analyze! Crafting Your Data in Qualitative Research, written with Jens Rennstam and published in 2018. Other interests include narrative analysis, social psychology, disability studies, and ethnomethodology. At the moment he is working on two projects, one on accessibility for people with disabilities in urban and digital settings, and another one on people's digital discussions and crowd sourcing activities around criminal events.

email address: david.wasterfors@soc.lu.se

Sophia Yakhlef is a Lecturer at the Department of Sociology, Lund University, Sweden. She received her PhD in sociology in 2018. Her research interests include collaboration, border policing, migration, gender, identity, masculinity, organization culture, the sociology of meetings, and emotion management. She is currently researching the role of humor in police collaboration, successful collaboration, and achievements, obstacles, collaboration, and identities in senior high school work with students who use alcohol and drugs.

email address: sophia.yakhlef@soc.lu.se

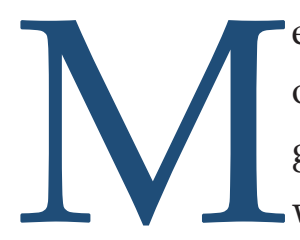

eetings are an omnipresent part of many workplaces and taken for granted as a way of organizing work, but several scholars stress that they are overlooked in most academic studies (Schwartzman 1989; Van Vree 1999; Allen, Lehmann-Willenbrock, and Rogelberg 2015). A recurring theme in various studies is complaints about meetings, particularly regarding their perceived meaninglessness. Employees argue that meetings take time from what they consider their core tasks (Schwartzman 1989:82; Kello 2015:713-714). Yet, the meeting society is being reproduced again and again. There seem to be hidden ways to incorporate meetings into today's working life without arousing critique about pointless activities and deviations from what should really be done.

Here, we analyze a particularly illuminating case that combines EU cooperation, well-known for its intense meeting and conference culture, and po- lice work, which is equally well-known for praising action and quick results in the streets rather than negotiations around a table. We want to explore how field-members protect their definitions of "real work" against a heavily bureaucratized transnational cooperation, so that their core conceptions can be kept within contemporary demands of working life. By doing so, we want to contribute to explaining the reproduction of meetings as a standard way of working, "the accomplishments of meetings as a form" (Schwartzman 1989:38), by analyzing how people's actions are "mixed or mixed up" (Schwartzman 1989:38) by this form. We argue that, to conceptualize how this is happening, we need to not only put meetings in the foreground of attention (Schwartzman 1989:39), but also employ a theory of members' everyday boundary work.

Our case consists of a transnational and inter-organizational project concerning border police in the Baltic region that aims to improve cooperation 
and find new ways to bridge different organizations, each with its own bureaucratic regulations. As such, this project was similar to many others. Organizing tasks in project forms are often seen as an opportunity to create flexibility, dynamics, and change in contemporary organizations, and they are "perceived as a controllable way of avoiding all the classic problems of bureaucracy" (Packendorff and Lindgren 2014:7). Despite this, as an EU project, many administrative efforts were demanded. These bureaucratic demands conflict with the ideal image of the police, as their occupational culture and identities have been described as pragmatic, anti-theoretical, and celebrating "action" (Reiner 1985; Chan 1997; Loftus 2010).

For example, Manning (2007:70) pointed out that even members of the top command within police organizations may "think of themselves as 'good police officers,' and emphasize their 'street smarts,' 'toughness,' or past crime-fighting successes rather than their administrative skills, wisdom as 'people managers,' or their educational achievements." The defining elements of police culture, for both street cops and management cops (Reuss-Ianni 2011), are a celebration of masculine ethos, policemen as crime-fighters with an imagery of conflict and danger, in contrast to bureaucratic tasks, meetings, and paperwork. However, the project we studied was actually made up of administrative tasks and formal meetings and was still considered a success due to it being "hands-on."

This article is based on descriptions and interactions involving these meetings, collected via conversational interviews and ethnographic field notes (Emerson, Fretz, and Shaw 1995). The study aims to illustrate how the police, through boundary work, maintain a recognizable police identity in face of the bureaucratic demands involved in this project, including many meetings. We note how some meetings came to be defined as "real" police work, whereas other meetings were considered bureaucracy, close to non-police work. In doing so, field-members managed to continue having meetings and still present their activities as real police work. The theory we suggest belongs to the anthropological framework in which meetings are seen as a form within which actors "transact, negotiate, strategize, and attempt to realize their specific aims" (Schwartzman 1989:37), but we want to enlarge this framework to also encompass practices that manipulate or reconstruct the emic limits of this form.

\section{Background: The Turnstone Project}

Since enlargement in the early 1990s, the EU has tried to facilitate cross-border and transnational cooperation. For example, the EU Security Policy ${ }^{1}$ aims to avoid political confrontation, environmental threats, and destabilizing regional conflicts through intense cooperation in many areas, from justice and home affairs to security and defense. Such efforts are achieved in various ways. This article concerns one such enterprise, a project called Turnstone, that united border police organizations involving several countries in the northern Baltic Sea area. ${ }^{2}$ Countries were to cooperate in surveillance of the "border

\footnotetext{
${ }^{1}$ See: http://www.consilium.europa.eu/uedocs/cmsUpload/78367. pdf. Retrieved June 19, 2020.

${ }^{2}$ As stated in the project application, enlargement of the Schengen area in 2007/2008 demanded international cooperation and inspired new methods of guarding the border. Project Turnstone was an extension of previous collaborative projects between EU countries in the Baltic Sea area. The goal of the project (as stated in the application) was to increase law enforcement cooperation between border agencies. The participating border agencies were: 1) the Police and Border Guard Board in Estonia, 2) Helsinki Police, 3) the Gulf of Finland Coast Guard District in Finland, 4) the State Border Guard of the Republic of Latvia, 5) the State Border Guard Service at the Ministry of Interior of the Republic of Lithuania, 6) Stockholm County Po-
} 
free" area because all are members of the Schengen area. The project was initiated by the Stockholm County Police, Border Division, in Sweden, and was introduced in January 2014 and co-funded by the European Union, Stockholm Police, and the Police and Border Guard board in the Northern prefecture of Estonia.

The initiators of the project explained to us that "criminals don't respect borders," lamenting the decreasing materiality and territoriality of borders (for an analysis see: Loftus 2013; Colombeau 2017). Simultaneously, they explained that the police encounter obstacles created by their national borders when trying to retrieve these criminals, as well as by the structures, rules, and routines of their own organizations. Furthermore, they described a situation in which they did not know enough about each other's organizations to understand which sections or people to contact when needed. The launch of the project was described as an opportunity to create mutual knowledge of each other's organizations that could help overcome these difficulties and escape the rigidity of the various organizations. The hope was to create personal networks that allow shortcuts through the bureaucracy.

The project was made up of meetings. In the detailed list of project activities in the application sent to the EU, which also governed the work, all activities referred to different meetings. ${ }^{3}$ The activities seen as binding were Management Board meetings, Intelligence group meetings, Operative Action group meetings, and a final conference. A number of other sub-meetings evolved more or less sponta-

lice, Border Police Division, and 7) the Swedish Coast Guard, Region Northeast.

${ }^{3}$ CIPS/ISEC 2012, Technical annex-detailed list of project activities. neously during the project, such as morning meetings, decision meetings, section meetings, telephone meetings, and quarterly meetings. The most formal meeting was the Management Board meeting. The ones that gathered the most participants were the "kick-off" meeting and the two conferences that concluded the project. The first of these conferences included workshops involving the participants, and the second was a large conference with internationally well-known researchers in the field of policing.

The project formally aimed to make representatives from the participating organization meet and work together in a hands-on manner. For this purpose, Operative Action group meetings were planned, meetings that were later renamed as "power weeks." During these occasions, representatives from the different organizations and countries were to get together and carry out, collect, and compare intelligence information. Meetings were often organized in meeting chains. For example, before a power week, the organizers held an Intelligence group meeting, and after the power week, the project leader, coordinator, and those responsible for organizing the power week met and evaluated the power week in another meeting.

\section{Meetings and Boundary Work}

During the fieldwork, it soon became clear that not all encounters, gatherings, and events were called meetings. This discovery triggered us to ask, "What meaning did the involved border police officers attach to "meetings?"" "How did the police officers manage to reconcile these bureaucratic expectations with their strong feelings about 'real' police work?"

The social anthropologist Helen Schwartzman (1989:7) defined meetings in terms of focused in- 
teraction. A meeting is a communicative form or standard situation with at least three persons (later revised to at least two persons) ${ }^{4}$ and characterized by multiparty talk. The participants of a meeting assume that this talk will concern the subjects described as the aim of the meeting. In the anthology Handbook of Meeting Science, the editors suggest that meetings at work are events that have been arranged beforehand, can be arranged face to face, and often take place in special rooms (Allen et al. 2015:4). However, they emphasize that this definition does not exhaust the potential variety of meetings. Schwartzman's definition emphasizes social phenomena, whereas Allen and colleagues concentrate on more concrete, practical issues. Thus, the academic definitions are not clear-cut. To add to the complexity, ambiguity is an inherent property of work-life language itself, as its lexical elements tend to be imprecise and words tend to acquire various associations. This imprecision is enhanced in contemporary meanings of meetings, as there is an increasingly broader continuum of variants of meetings and a tendency of increasing informality during meetings (Van Vree 2011). The tendency is interrelated with technological changes; people may engage in multitasking or "being in two places at once" during meetings. Thus, meeting participants may both engage in focused interaction with other participants and in side-involvements on their laptops or smartphones (Wasson 2006; Kleinman 2010).

Increased informality is also indicated in the meeting industry's appropriation of "meetings," so that meetings may last for many days and take place outdoors, in resorts, or in hotels. Such meetings are

" Lecture: "The Dance and the Drama of Meetings: An Anthropological Perspective," Higher seminar, Department of Sociology, Lund University, May 20, 2016. supposed to enhance creativity and create more effective meetings, enacted with a rhetoric of emotional involvement (Andersson Cederholm 2010). Such meetings are portrayed as being different from typical workplace meetings, which occur in an office setting, often last for about 60 minutes, and have a predetermined agenda (Allen et al. 2015:4).

To analyze the definitions and distinctions regarding meetings among the police officers in our study, we have utilized the concept of boundary work. Symbolic boundaries involve "distinctions made by social actors to categorize objects, people, practices, and even time and space" (Lamont and Molnár 2002:168). Researchers have studied how people construct boundaries around various activities, conditions, or types of people. Boundary work has been used to analyze various and different social phenomena, such as what is defined as science (Gieryn 1995), in work-life in regards to responsibilities and tasks belonging to different occupations (Allen 2001), the social construction of violence (Åkerström 2011; Uhnoo 2011), and in interactions other than talk, as in gender boundaries activated in play situations (Thorne 1999).

In the present case, the boundary work was mostly implicit. Police officers defined some events as meetings, or "regular meetings" as one officer called them, including the formalistic paraphernalia, atmosphere, and seating. Others, such as Operative Action group meetings, or as they were later called, power weeks, were not defined as meetings, but belonged to the sphere of "real" police work. These were events in which a smaller group of officers from the participating countries gathered to collect and compare intelligence information. Field-member's ways of dodging the meeting label and calling 
it something else turned out to be closely associated with increasing informality, as well as multitasking, during these gatherings.

\section{Material and Methods}

This study relies on empirical data gathered through fieldwork and qualitative interviews conducted in seven border and police organizations in Estonia, Finland, Latvia, Lithuania, and Sweden during a 2-year period. ${ }^{5}$ Our study not only incorporates the "street cops," who have been the focus of many ethnographic studies describing police occupational culture, but also both lower rank intelligence officers and middle and top managers. The top managers were present in the start-up and ending conferences; and the rest took part in all other activities. Most officers took part in the whole project, but some persons were exchanged. The representatives were evenly divided from the different countries and organizations.

The fieldwork consisted of several shorter visits, a few days to a week at a time, at the different border agencies and can be described as multi-sited fieldwork (Hage 2005). Field observations were gathered over 718 hours during work sessions, everyday border guard or police work, project-related meetings, and day-to-day office work.

All of us did some field work; we participated in the planning stages and the start and ending meetings that were larger workshops and conferences. One of us, Sophia Yahklef, collected most of the data and participated in the power weeks, which are the focus of this article. Four power weeks occurred in

${ }^{5}$ The data were gathered in 2014-2015 and are further described by Yahklef (2018).
2014 and four in 2015. They lasted 5 working days, from Monday to Friday, and each engaged between 8 and 20 participants. The same officers (with some exceptions) participated in all of the activities. The majority of the participating officers were male, and the number of females participating in the power weeks varied between one and six.

During these meetings, the field researcher took notes on a notepad or in a notebook. As highlighted by the social anthropologist Thedvall (2006:32), meetings offer the researcher an excellent opportunity to pay attention to the members while also being able to take notes. In addition to taking notes on what was said during the meetings, the researcher focused on describing the tone of voice and facial expressions of the members and noted instances when the members looked bored; looking at their smartphones, doodling, or otherwise preoccupied.

The interviews conducted for this study focused on the interviewees' experiences in border work, involvement in national and international cooperation, and other issues that they found to be important regarding their job positions and organizations. The interviews took the form of active interviews, in which the interviewees were considered narrators who, together with the interviewer, co-constructed a story or description of a phenomenon (Holstein and Gubrium 1995). The interviews were usually conducted at the offices of the people being interviewed or in a conference room at the interviewee's workplace. A few times, informal conversations that were not recorded occurred at cafes or restaurants. A total of 73 interviews were conducted, some rather short (15-20 minutes), but most longer (1-1.5 hours). Six to 15 people from each participating organization were interviewed. 
There were fewer women than men involved in the project, resulting in 13 interviews with female officers and 53 interviews with male officers.

Conversations and interviews with informants were conducted in English or Swedish. The work language spoken by the officers during joint meetings or actions was mainly English, but at times they would also use Russian, Swedish, Finnish, Estonian, Lithuanian, and Latvian when speaking to each other. The third author used Swedish and English, but a postdoc ${ }^{6}$ working on the project also knew enough Russian to be able to understand some of the occasional small talk between those who spoke this language.

We informed the interviewees and participants about the purpose of the study, anonymity, and that participation is voluntary. The names of people and places involved in the research, as well as other information that could identify the interviewees, have been changed for this article and other presentations related to this study.

The analysis in the present article was inspired by an interest in meetings and earlier case studies of work-place meetings (Åkerström 2018; Thelander and Åkerström 2019). Vaughn (2015), who was inspired by Simmel's formal sociology, argued for the advantages of exploring a particular phenomenon with qualitative case studies. This is one such case study that we hope will shed more light on the under-researched topic of work-place meetings. The study should be assessed on its transferability rather than traditional generalization, with application to other potential analysis (Fangen 2005:276).

\footnotetext{
$\overline{{ }^{6} \text { Docent Goran Basic. }}$
}

\section{Portrayals of Formal Meetings}

From the beginning of the project, the participants warned against the project becoming yet another effort with many meetings between people at a managerial level. The participants emphasized that this project should be more hands on, consisting of "real police work" and not just "regular meetings." During the first planning meeting at a large conference hotel on the outskirts of Stockholm, Sweden, suggestions to integrate anything that "smelled administration" or management activities were resisted. The participating officers had all gathered in a conference room, talking about the development of the project. For example, when one officer mentioned the need for organizational development, a high-level officer sitting further down at the U-shaped conference table objected forcefully to this suggestion. Leaning back in his chair and folding his arms, this officer declared with a loud and decisive voice that it was important to remember that:

This project is meant to be on street level involving practical cooperation, establishing more partners. It should be about real work, it is important with some structure, but we don't need to create a huge organization, we just need to work together. [Fieldnotes 2014]

The large group at this first meeting was later divided into groups. In one of the group discussions in which a field observer was present, the ambition to turn the project in a hands-on direction was emphasized. One participant explained how other EU police cooperation projects that he knew about had turned out to be "long meeting circuses" ending with nothing but documents and no practical results. He talked about a "collaborative diplomacy" going on year after year: 
In previous cooperation, it has often been hard to find, officially it's not hard to find common ground, the gentlemen meet and shake hands and say "yes" and agree, and so on, but when it comes to what to do specifically, it's harder to know what we are talking about.

Such a contrast structure (Smith 1978), in this case the linguistic dichotomous distinction between the "real job," where things got done through practical work, and bureaucratic meetings where things did not get done, were evident in most interviews and field observations collected during the whole time the project lasted. There was a recurring discursive practice of drawing a line between "meeting circuses" and what should really be done.

When the project started, one of the field researchers asked a participant at a border police station if there had been too many meetings in the project. The police officer said, "not so far." Still, the warnings persisted. He added that, even though the situation was acceptable at the moment, he was afraid that the project could change to being held at a "meeting level," saying, "I've had that experience before and never been pleased with it." Closely tied to this argument was skepticism towards managers and their purported unrealistic talk. Another interviewed intelligence officer from Finland expressed his hope that Turnstone would stay at "the right level, shop level, and not only a lot of bosses who just talk. This is not a forum for discussion, but seeing that there will be results."

The project members' way of talking about formal meetings corresponds to common cultural assumptions that meetings often consist of "empty talk" that may not lead to anything substantial, and meetings give managers with little knowledge of the reality too much influence. Kello (2015) pointed to descriptions of meetings as meaningless and dull and meeting participants as affected by meeting fatigue. In Bargiela-Chiappini and Harris (1997), a comparative study of meetings in two British and Italian companies, even their studied managers criticized their own meetings as merely talk or inaction. Thus, this meeting critique is widespread, but in our study formal meetings were especially adverse to the police occupational culture and policemen's identity as people of action. Therefore, the discursive and practical boundary work that could be observed was crucial.

Consider the instances when the field-members were ambivalent towards the meeting frame, such as when they performed mini "shows" when fetching coffee, candy, or chocolate from the always present coffee table in the conference rooms by stating loudly that "this is the kind of food that creates crime-fighters," by doing a little dance, and exchanging jokes contrasting the conference rooms and their activities and paraphernalia (computers and papers) with images of "elite gang busters." In these and similar ways, the participants demonstrated distance from formalities and rigidity, thereby celebrating action and downgrading meetings, sometimes with self-irony.

We could not find any differences among the participating members from various countries regarding their stances towards formal meetings; they all seemed to embrace the meeting critique discourse. However, national characteristics in relation to meetings could be used in the joking relationship that developed among the officers over time. For example, though the Swedes could be teased for their tendency to arrange "long and boring meetings," the Swedish officers could claim that their Finnish colleagues were hardly able to hold a telephone 
meeting, "Three minutes are what they can master. No more."

\section{Meetings Become Real Police Work}

Project members relabeled Operative Action group meetings as power weeks because the latter name, according to the officers, was "boring and complicated." However, the new name was not only less boring and less complicated, but also entailed more action, according to one officer. Another important facet of the name change was perhaps the disappearance of the word "meeting."

So what did these power weeks entail? They gathered a team of officers from Estonia, Finland, Latvia, Lithuania, and Sweden in the different countries for 1 week at a time. The team was tasked with processing and investigating information regarding ongoing or border-related criminal activity. The idea was that this select group of people would get to know each other's organizations by working closely together during different work-related activities and, in the process, establish personal relationships. Each week had 8-20 participating officers working together. Usually, the same officers (with some exceptions) participated on each occasion, and most of the participating officers were men.

The power weeks were referred to as proper police work, whereas other meetings were not. At times, the contrasting structure (cf., Smith 1978) between formal meetings and meetings falling under the concept of power weeks was very visible. Consider, for example, this field note made during a meeting in Stockholm with the project leaders:

The project leader and his assistant talk about how they have taken away one of the meetings to be able to finance yet another power week. "We don't need another bureaucracy meeting, the bosses may have to do a study visit in reality."

It is evident that, in this explicit boundary work by the police officers, power weeks do not constitute meetings because they have taken away a meeting to make room for a power week. Furthermore, a meeting is associated with bureaucracy, whereas power weeks are associated with reality. Mostly, however, the boundary work was implicit.

So how did the power weeks escape being associated with meetings? To answer this, we took a detailed look at how they worked.

A typical day would go as follows. The officers arrived and placed their laptops, phones, coffee mugs, and water bottles on the conference table. The inviting officer gathered everybody and asked for their attention, a sort of "start-up meeting" in which everybody was informed, for example, about cars stolen in one of the Nordic cities the previous evening, and the participants were then asked if they could add any information. The officers checked their computer systems, and one border officer made a phone call to his colleagues in the harbor. If no one had any questions to ask, the meeting was adjourned after a few minutes. The officers then turned their attention towards their laptops or phones. They opened their programs, searched for information within various systems, wrote emails and messages, checked media web pages, and tried to tie together information on the border-related crime activities in question. Occasionally, the officers asked each other questions, received telephone calls, or told the others when they acquired information about a suspect or recently committed crime. Gradually, persons of interest or ongoing surveillance were listed on 
a large whiteboard at one end of the room. A border officer sat at one end of the table and took notes on all ongoing activity in an Excel document.

When the officers found something that they thought was interesting, they could comment loudly on this fact, at times engaging in talk with the whole group or with a few others. Occasionally, they got up to get some coffee, wrote something on a whiteboard, or went to the bathroom.

The workdays also provided occasions for jokes and bantering. The border and intelligence officers frequently shared stories and jokes about toughness and bravery or dangerous encounters with criminals. These stories often caught everyone's attention and provided a pause during work. Officers discussed action or police films that they had seen or made ironic comments about heroes who they did not resemble but still somehow admired. With this, as in joking about boring emails, the officers engaged in "contrast work" between the expressed ideal in police occupational culture and the reality of their situation.

The officers demonstrated high commitment to their work. They worked long hours, typically staying in the conference room from 8 o'clock in the morning to 9 o'clock in the evening. At times, they waited to leave for lunch until 3 o'clock in the afternoon. Some had been up early, travelling to the power week, and often looked red-eyed and tired. Although appearing tired, the participating officers often engaged in amiable small talk and seemed to be relaxed in each other's company. At the same time, the participants focused on their electronic work tasks and immediately changed their "purely social" manners if something they deemed important was found. The work achieved many hits; that is, together they found many suspects who were of interest for surveillance because they operated in more than one country. However, most of the time, the hits were not followed up, and few arrests or substantial findings were made during the power weeks.

\section{Boundary Work in a Police Cooperative Project}

Through the above-described scenes, we can see that the power weeks offered an alternative and relatively free type of interaction compared to the formal or regular meetings. The officers could each be involved in their own digital work, and they were not disciplined by a conventional meeting culture with its demands of a collective focused attention and quite formal way of talking. When asked about what "meetings" meant, the policemen mentioned board meetings or management meetings, not these power weeks. They seemed to associate a proper meeting with Van Vree's (2011) description of modern meeting culture, an interactional ceremony of gatherings involving disciplining gestures and emotions. In a meeting, people are supposed to stick to the subject, taking turns at talking and voicing opinions in measured and balanced ways, while the chairman should intervene "courteously." Such gatherings imply meeting competence in terms of having a chair, having and keeping to the agenda, writing a protocol, and knowing about voting rules and keeping to the proper roles and manners.

Power weeks were meetings that obviously did not fit into such a form. They were placed outside this category by subtle boundary work consisting of discursive and practical elements. First, "meetings" disappeared linguistically. This disappearance oc- 
curred early on in the project with the renaming to power weeks, as this name was declared less boring and more sexy. Throughout the project, in everyday talk among the police officers and in interviews, police officers in project Turnstone stuck to the use of "power weeks," whereas the original name was forgotten.

More than discursively delineating meetings from power weeks, interaction other than talking may serve as boundary work (Thorne 1999). Moving around in the conference room, feeling free to take breaks whenever one wanted, working at one's laptop in a seemingly immersed way, improvising interruptions by telling stories and jokes, these ways of navigating the long days of being situated in a social gathering can also be seen as doing boundary work. Thus, the police officers employed not only discursive methods to demarcate in relation to the image of meetings, but also practical methods. By interacting in certain ways and continually performing, and joking about, an action-oriented ideal of real police work, the members managed to keep having these EU-initiated "meetings" without jeopardizing their police ethos. On the one hand, the gatherings during power weeks did not resemble a formal meeting with an agenda, turn-taking, and sitting still during a fixed period of time. On the other hand, police officers from several countries and organizations did accomplish workplace meetings.

Some boundary work during power weeks turned explicit, as when certain gatherings within the week were actually named "meeting" (underlining that the rest of the week were not "meetings"). In the morning, for example, a start-up meeting was always enacted, when the officers went through past events and planned the upcoming week. Another example was, during the course of the day, when some- one announced that they should have "a meeting."7 The groups sort of mobilized and became focused or "collected," even though they actually were already assembled in the same room; the participants looked up from their screens and their mouse-clicks and small talk stopped, and there was one speaker at a time with joint attention. These meetings were brief and concerned work regarding important "high profile cases," such as thefts, robberies, or smuggling performed by members of international organized crime groups. As these groups operated in several countries, many officers were involved in these cases and were eager to share information regarding these crime groups. Such involvement can be contrasted with the project's formal meetings in which many points on the agenda did not concern all participants, but rather the EU cooperation as a whole. The police officers never frowned upon these more or less spontaneously called meetings within the power week. They were not described the way formal meetings were, as "just talk," diplomacy, or bureaucracy, but considered as "real police work."

\section{Discussion}

Social interactions through meetings constitute a large part of the everyday lives of not only bureaucrats and managers, but of many employees. Meetings are an omnipresent part of many contemporary social contexts, and what occurs in meetings affects many more beyond the meeting participants. However, several scholars stress that meetings are overlooked in most academic studies (Schwartzman 1989; Van Vree 1999; Allen et al. 2015). One puzzling aspect worthy of further in-

\footnotetext{
${ }^{7}$ In the first power week, the field-worker was asked to leave during such meetings, a demand that was not voiced later.
} 
vestigations is the abundance of meeting critique (Hall, Leppänen, and Åkerström 2019) parallel to a process of "meetingization of society," an increasing number of meetings in Europe (and other places) (Van Vree 2011).

Through an illuminating case of a collaboration project between border police in the Baltic region, we could explore how representatives of an occupation identifying with action and pragmatic work relate to the demands of formal meetings. How could they protect their definitions of "real work?"

The dislike of bureaucratic practices, such as writing reports and having meetings, is well documented in studies of police culture. Reiner (1985:103) and Chan (1997:343) note that a pragmatic, anti-theoretical perspective is a typical occupational habitus for street-level police officers, and it is also supported and celebrated by high-ranking officers (Manning 2007). Our case included not only intelligence officers, but also border police at a managerial level. They all supported what came to be described as the project's "hands-on profile." This profile was explained as a contrast to projects that consisted of a lot of meetings at a managerial level.

At the same time, project Turnstone was its meetings. In the original proposal to the EU, the many activities that were listed and subsequently completed consisted of meetings, from the initial kick-off meeting to the finishing conference. Despite this density of meetings within a work atmosphere praising the opposite, the project was declared a success by those involved. At the end of the project, during a final conference, some of the participating officers emphasized the lack of administration and meetings and used this as an explanation for why they considered the project a success.
This paradox can be explained by the fact that the project members engaged in multifaceted boundary work (Lamont and Molnár 2002). We have tried to show both discursive and practical variants of such boundary work in situ. Some social gatherings were pronounced as meetings, whereas others were placed outside this category. Navigating within a heavily bureaucratized project, police officers came to accomplish some meetings as a form of work gathering without necessarily using the term "meeting" or the associated patterns of interactions, so that they could devotedly join an EU collaboration and still protect and perform their police identity. With the help of ethnographic studies close to everyday gathering practices, we could discover such subtle manipulations or reconstructions of emic limits.

Ironically, one may argue that the power weeksour prime example-were meetings; with their casual and loose character, they seem to fit well into today's tendency to informalize this working form (Van Vree 2011). Yet, members found ways around this category.

\section{Conclusion}

To conclude this article, we would like to highlight some complexities. First, formal meetings in project Turnstone, such as the management and board meetings, did not fit into "real police work," but they were described by all participants as a "necessary evil" and, consequently, tolerated. Managers had to negotiate and agree, plans had to be made, and finances had to be acquired and budgeted. Formal meetings had to exist, field-members argued, but they did not really belong to proper police work. In this respect, some of the boundary work we have found around meetings can be seen as being 
quite close to or overlapping what scholars refer to as actors' definitions of "dirty work." Emerson and Pollner (1976) elaborated on Everett Hughes' concept that pointed to the moral division of labor in a society in which some occupations are degraded. In their study of a psychiatric emergency team, Emerson and Pollner (1976) concluded that some tasks in a given occupation may be among the least desirable to emphasize their occupational identity. In this way, "representatives for a profession or occupation mark a moral distance to certain parts of their work so that they confirm the preferred moral order by pointing out that some tasks do not belong to their 'true occupational self'"' (Emerson and Pollner 1976:244).

Second, project Turnstone could not escape the bureaucratic practices of the EU, which included ambitious documentation, collected in part during meetings. However, even these least appreciated parts of the project came to be, if not appreciated, accepted. They may even have contributed to the sought-after creations of social bonds by providing an arena for mutual agreement of their relative meaninglessness. During some project-related meetings, for example, the participants would occasionally roll their eyes and laugh together at such seemingly unnecessary activities, such as filling in participation lists or adding the EU logo to every PowerPoint slide in a presentation. These activities came to be expected and were eventually taken for granted, and there were some enjoyable aspects within them.

Third, formal meetings were continuously described in ways that characterized them as undesirable and placed them in a category that was outside "proper police work." The assumption that "nothing gets done" during most formal meetings corresponds to a rationalistic or instrumental evaluations of meet- ings. Meetings are meant to solve problems and achieve results. Police officers continually contrasted "getting things done" with "just talking." This rationalist norm is also strongly prevalent in the widespread criticism of pointless meetings, within and outside project Turnstone. Much meeting criticism is part of an instrumentalist and moralist worldview. In their comparative study of meetings in two British and Italian companies, Bargiela-Chiappini and Harris (1997:6) highlighted this criticism because it was constantly reiterated by the directors in their study-meetings are "talk," and because talk is not seen as action, meetings could be interpreted as the opposite, as inaction.

Fourth, one could argue that the power weeks did not achieve much more than creating a lot of pooled information, which were often not followed up (there were few arrests, which was considered the most important goal by most officers). In addition, things "got done" during formal meetings (plans were made and decisions made). Power weeks were appreciated because they offered a special social form beyond those involved in the formal meetings and protected the police ethos. During these gatherings, the officers were not socially and emotionally disciplined according to conventional meeting culture, the business meeting culture in Van Vree's terminology (2011), demanding collective, focused attention even when the discussion did not involve or engage them. They performed boundary work by acting outside of the archetypical meeting frame. The officers made frequent excursions from their work by engaging in small talk, telling jokes, and sharing stories. They presented an image of emotionally involved quick thinking and humorous professionals, in contrast with the stereotypical image of the restrained bureaucrat, obeying rules, a soulless executor of orders from above (Mahmood 2017). This 
was a social type the policemen explained were interested in "meetings." Other studies have hinted at other ways to downplay the demands of a meeting frame in which professionals engage; professionals who do not identify with a meeting culture, but define their core activities in other ways. Doctors and nurses in Hall's (2012) study sometimes stood up in the staff meetings on quality management, answering calls and leaving if someone from their ward called them. This was in stark contrast to staff in a university context or civil servants in municipality organizations attending the same type of meetings.

\section{References}

Åkerström, Malin. 2011. "Slaps, Punches, Pinches-But Not Violence: Boundary Work in Nursing Homes for the Elderly." Symbolic Interaction 25(4):515-536.

Åkerström, Malin. 2018. "The Merry-Go-Round of Meetings: Embracing Meetings in a Youth Care Project." Sociological Focus 52(1):50-64.

Allen, Davina. 2001. "Narrating Nursing Jurisdiction: Atrocity Stories and Boundary-Work." Symbolic Interaction 24(1):75-103.

Allen, Joseph, Nale Lehmann-Willenbrock, and Steven Rogelberg, (eds.). 2015. The Cambridge Handbook of Meeting Science. Cambridge: Cambridge University Press.

Andersson, Cederholm E. 2010. "Effective Emotions: The Enactment of a Work Ethic in the Swedish Meeting Industry." Culture Unbound: Journal of Current Cultural Research 2:381-400.

Bargiela-Chiappini, Francesca and Sandra Harris. 1997. Managing Language: The Discourse of Corporate Meetings. Amsterdam: John Benjamins Publishing Company.

Chan, Janet. 1997. Changing Police Culture. Cambridge: Cambridge University Press.

Colombeau, Sara C. 2015. "Policing the Internal Schengen Borders-Managing the Double Bind between Free Movement and
Finally, during power weeks, members of our study could hope for "a situation of action," even though having a (formal) meeting was described as meaningless and boring. Information gathered during these events was supposed to lead to "real" transnational police work in the form of chasing and arresting border-crossing criminals. They considered themselves to be in a sort of "stand-by" mode, basically ready for action and digitally engaged in the idea of action because their activities were defined as close to their criminal cases. In formal meetings, there was no such hope.

Migration Control." An International Journal of Research and Policy 27(5):480-493.

Darden, Donna and Alan Marks. 1999. "Boredom: A Socially Disvalued Emotion." Sociological Spectrum 19:13-37.

Emerson, Robert M., Rachel Fretz, and Linda Shaw. 1995. Writing Ethnographic Fieldnotes. Chicago: University of Chicago Press.

Emerson, Robert M. and Melvin Pollner. 1976. “Dirty Work Designations: Their Features and Consequences in a Psychiatric Setting." Social Problems 23(3):243-254.

Fangen, Katrine. 2005. Deltagande observation [Participant Observation]. Malmo: Liber.

Gieryn, Thomas. 1995. "Boundaries of Science." Pp. 393-443 in Handbook of Science and Technology Studies, edited by S. Jasanoff. London: Sage.

Hage, Ghassan. 2005. "A Not So Multi-Sited Ethnography of a Not So Imagined Community." Anthropological Theory 5(4):463-475.

Hall, Patrik. 2012. Managementbyråkrati [Management Bureaucracy]. Malmo: Liber.

Hall, Patrik, Vesa Leppänen, and Malin Åkerström. 2019. Mötesboken [The Meeting Book]. Malmo: Egalité. 
Holstein, James and Jaber Gubrium. 1995. The Active Interview. London: Sage.

Kello, John. 2015. "The Science and Practice of Workplace Meetings." Pp. 709-734 in The Cambridge Handbook of Meeting Science, edited by J. Allen et al. New York: Cambridge University Press

Kleinman, Lisa. 2010. Technology Multitasking in Organizational Meetings. PhD Dissertation, Texas University, Department of Information.

Lamont, Michèle and Virág Molnár. 2002. "The Study of Boundaries in the Social Sciences." Annual Review of Sociology 28:167-195.

Loftus, Bethan. 2010. "Police Occupational Culture: Classic Themes, Altered Times." Policing and Society 20(1):1-20.

Loftus, Behtan. 2013. "Border Regimes and the Sociology of Policing." An International Journal of Research and Policy 25(1):115-125.

Mahmood, Qaisar. 2017. “En gravallvarlig figur i demokratins tjänst [A Solemn Figure in the Service of Democracy]." Fokus 45:42.

Manning, Peter. 2007. "A Dialectic of Organizational and Occupational Culture." Pp. 47-83 in Police Occupational Culture, edited by M. O'Neill, M. Marks, and A.-M. Singh. Amsterdam: Elsevier JAI Press.

Packendorff, Johann and Monika Lindgren. 2014. "Projectification and Its Consequences." South African Journal of Economic and Management Sciences 171:7-21.

Reiner, Robert. 1985. The Politics of the Police. Brighton: Wheatsheaf.

Reuss-Ianni, Elizabeth. 2011. Two Cultures of Policing: Street Cops and Management Cops. New Brunswick, NJ: Transaction Publishers.
Schwartzman, Helen. 1989. The Meeting: Gatherings in Organizations and Communities. New York: Springer Science.

Smith, Dorothy. 1978. "K is Mentally Ill. The Anatomy of a Factual Account." Sociology 12(1):23-53.

Thedvall, Renita. 2006. Eurocrats at Work. Negotiating Transparency in Postnational Employment Policy. PhD Dissertation, Stockholm Studies in Social Anthropology, 58, Stockholm University.

Thelander, Joakim and Malin Åkerström. 2019. “Ruled by the Calendar? Public Sector and University Managers on Meetings, Calendars and Time." Sociologisk Forskning 56(2):149-165.

Thorne, Barrie. 1999. Gender Play: Girls and Boys in School. New Brunswick, NJ: Rutgers University Press.

Uhnoo, Sara. 2011. Våldets regler [Rules of Violence]. Goteborg: daidalos.

Van Vree, Wilbert. 1999. Meetings, Manners and Civilization: The Development of Modern Meeting Behaviour. London: Leicester University Press.

Van Vree, Wilbert. 2011. "Meetings: The Frontline of Civilization." The Sociological Review 59(1):241-262.

Vaughn, Diane. 2015. "Theorizing: Analogy, Cases, and Comparative Social Organization." In Theorizing in Social Science, edited by R. Swedberg. Stanford: Stanford University Press.

Wasson, Christina. 2006. “Being at Two Spaces at Once: Virtual Meetings and Their Representation." Journal of Linguistic Anthropology 16(1):103-130.

Yahklef, Sophia. 2018. United Agents. Community of Practice within Border Policing in the Baltic Sea Area. Dissertation Series 119, Lund University, Department of Sociology.

\section{Citation}

Åkerström, Malin, David Wästerfors, and Sophia Yakhlef. 2020. “Meetings or Power Weeks? Boundary Work in a Transnational Police Project." Qualitative Sociology Review 16(3):70-84. Retrieved Month, Year (http://www.qualitativesociologyreview.org/ ENG/archive_eng.php). DOI: http://dx.doi.org/10.18778/1733-8077.16.3.05 